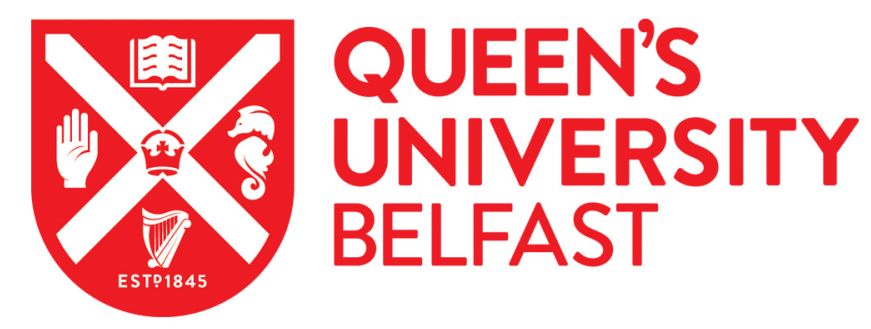

\title{
A comprehensive examination of the model underlying acceptance and commitment therapy for chronic pain
} Vowles, K. E., Sowden, G., \& Ashworth, J. (2014). A comprehensive examination of the model underlying
acceptance and commitment therapy for chronic pain. Behavior Therapy, 45(3), 390-401.
https://doi.org/10.1016/j.beth.2013.12.009

Published in:

Behavior Therapy

Document Version:

Peer reviewed version

Queen's University Belfast - Research Portal:

Link to publication record in Queen's University Belfast Research Portal

Publisher rights

Copyright 2014 Elsevier.

This manuscript is distributed under a Creative Commons Attribution-NonCommercial-NoDerivs License

(https://creativecommons.org/licenses/by-nc-nd/4.0/), which permits distribution and reproduction for non-commercial purposes, provided the author and source are cited.

\section{General rights}

Copyright for the publications made accessible via the Queen's University Belfast Research Portal is retained by the author(s) and / or other copyright owners and it is a condition of accessing these publications that users recognise and abide by the legal requirements associated with these rights.

Take down policy

The Research Portal is Queen's institutional repository that provides access to Queen's research output. Every effort has been made to ensure that content in the Research Portal does not infringe any person's rights, or applicable UK laws. If you discover content in the Research Portal that you believe breaches copyright or violates any law, please contact openaccess@qub.ac.uk. 


\section{Accepted Manuscript}

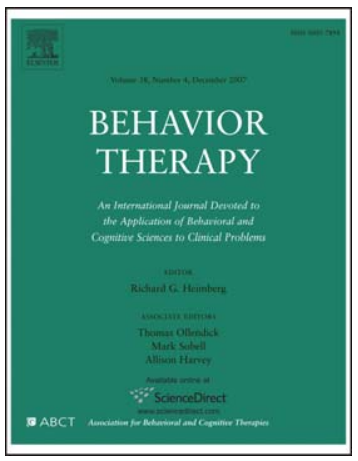

A Comprehensive Examination of the Model Underlying Acceptance and Commitment Therapy for Chronic Pain

Kevin E. Vowles, Gail Sowden, Julie Ashworth

PII:

S0005-7894(13)00142-1

DOI:

doi: $10.1016 /$ j.beth.2013.12.009

Reference: $\quad$ BETH 457

To appear in: Behavior Therapy

Received date: 25 July 2013

Accepted date: $\quad 24$ December 2013

Please cite this article as: Vowles, K.E., Sowden, G. \& Ashworth, J., A Comprehensive Examination of the Model Underlying Acceptance and Commitment Therapy for Chronic Pain, Behavior Therapy (2014), doi: 10.1016/j.beth.2013.12.009

This is a PDF file of an unedited manuscript that has been accepted for publication. As a service to our customers we are providing this early version of the manuscript. The manuscript will undergo copyediting, typesetting, and review of the resulting proof before it is published in its final form. Please note that during the production process errors may be discovered which could affect the content, and all legal disclaimers that apply to the journal pertain. 
Running Head: A COMPREHENSIVE EXAMINATION

\begin{abstract}
A Comprehensive Examination of the Model Underlying Acceptance and Commitment Therapy for Chronic Pain
\end{abstract}

Kevin E. Vowles ${ }^{1,2}$, Gail Sowden ${ }^{2,3}$, \& Julie Ashworth ${ }^{2,3}$

${ }^{1}$ Department of Psychology, University of New Mexico, MSC03 2220, Logan Hall, 1 University of New Mexico Albuquerque, NM 87131, United States of America ${ }^{2}$ Interdisciplinary Musculoskeletal Pain Assessment and Treatment Service, Haywood Hospital, High Lane, Burslem, Stoke-on-Trent ST6 7AG, United Kingdom

${ }^{3}$ Arthritis Research Campaign National Primary Care Centre, Keele University, Keele ST5 5BG, United Kingdom

13 December 2013

Correspondence to: Kevin E. Vowles, Ph.D., Department of Psychology, University of New Mexico, Logan Hall, MSC03 2220, 1 University of New Mexico, Albuquerque, NM 87131, United States of America, +1 505 277-5676, k.e.vowles@gmail.com (e-mail)

Keywords: Acceptance and Commitment Therapy, Chronic Pain, Structural Equation Modelling, Functioning, Multivariate Analysis 


\begin{abstract}
The therapeutic model underlying Acceptance and Commitment Therapy (ACT) is reasonably well-established as it applies to chronic pain. Several studies have examined measures of single ACT processes, or subsets of processes, and have almost uniformly indicated reliable relations with patient functioning. To date, however, no study has performed a comprehensive examination of the entire ACT model, including all of its component processes, as it relates to functioning. The present study performed this examination in 274 individuals with chronic pain presenting for an assessment appointment. Participants completed a battery of self-report questionnaires, assessing multiple aspects of the ACT model, as well as pain intensity, disability, and emotional distress. Initial exploratory factor analyses examined measures of the ACT model and measures of patient functioning separately with each analysis identifying three factors. Next, the fit of a model including ACT processes on the one hand and patient functioning on the other was examined using Structural Equation Modeling. Overall model fit was acceptable and indicated moderate correlations among the ACT processes themselves, as well as significant relations with pain intensity, emotional distress, and disability. These analyses build on the existing literature by providing, to our knowledge, the most comprehensive evaluation of the ACT theoretical model in chronic pain to date.
\end{abstract}




\section{A Comprehensive Examination of the Model Underlying \\ Acceptance and Commitment Therapy for Chronic Pain}

The experience of chronic pain is often associated with substantial distress and disability. There is now a well-established database indicating that psychological and behavioral processes are strongly related to patient physical and emotional functioning (see Gatchel, Peng, Peters, Fuchs, \& Turk, 2007 for a review).

Over the past 15 years, there has been increasing interest in the theoretical and practical utility of Acceptance and Commitment Therapy (ACT; Hayes, Strosahl, \& Wilson, 1999) as it applies to chronic pain. In brief, the focus of ACT for chronic pain is on assisting pain sufferers to engage in a flexible and persistent pattern of values-directed behavior while in contact with continuing pain and discomfort, particularly when efforts to control or reduce pain or discomfort have failed in the past or contributed to greater difficulties over the longer term (McCracken, 2005; Vowles \& Thompson, 2011). Treatment efforts involve assisting individuals with chronic pain to better achieve a more full, rich, and rewarding life, both when pain and discomfort are low, but importantly also when they are elevated or even at their maximum. The technical term for this overarching focus is psychological flexibility; its enhancement is the primary aim of ACT (see Hayes, Strosahl, \& Wilson, 2012 and Hayes, Villatte, Levin, \& Hildebrandt, 2011 for further discussion).

Originally, psychological flexibility was conceptualized as being composed of six overlapping component processes (Hayes et al., 2012). Briefly, these processes include:

(a) Acceptance, a broad based willingness to have pain or discomfort.

(b) Defusion, a lack of dominance of verbal, often cognitive, content or narrowing of perspective such that it is predominately focused on this content.

(c) Moment-to-Moment Awareness, a purposeful, non-judgemental, and fluid attending to present experiences.

(d) Self-as-Context, a conscious perspective taking on the content of one's experience where a distinction is made between the person having the experience and the experiences themselves. 
(e) Values Orientation, freely identified (e.g., non-coerced) directions for activity that bring meaning, importance, or vitality to living.

(f) Committed Action, a pattern of behavior that encompasses a flexible persistence oriented towards valued living.

More recently, Hayes and colleagues (2012) have discussed these six processes as three pairs of response styles, summarized as "Open" (Defusion/Acceptance), "Centered" (Moment to Moment Awareness/Self-as-Context), and “Engaged” (Values Orientation/Committed Action). This latter pairing of the ACT processes reflects their close relation to one another and was done to assist in clinical case conceptualization and treatment (Hayes et al., 2012). See also McCracken and Vowles (in press) for a discussion of these pairs of response options in relation to chronic pain specifically.

To date, there has been no examination of how data fit with either the three or six process ACT model. Instead, evaluation of psychological flexibility and its relevance to chronic pain has principally involved establishing the psychometric characteristics of measures and evaluating their relations with relevant aspects of patient emotional and physical functioning, as well as healthcare utilization (e.g., analgesic medication usage, painrelated medical visits). At the present time, there are a number of measures of ACT processes (e.g., values success, defusion, acceptance, aspects of mindfulness), which have been used in a diverse array of pain settings or diagnostic groups (e.g., adults, children and adolescents, primary care, tertiary care, musculoskeletal pain, neuropathic pain, HIV-related pain). These studies have established a reliable pattern of results - essentially, it is now clear that measures of psychological flexibility are strongly related to various aspects of patient functioning and usually account for a noteworthy amount of variance above and beyond other pain-related symptoms or cognitions (e.g., Elander, Robinson, Mitchell, \& Morris, 2009; Kratz, Davis, \& Zautra, 2007; McCracken, Gauntlett-Gilbert, \& Vowles, 2007; McCracken \& Zhao-O'Brien, 2010; Vowles, McCracken, McLeod, \& Eccleston, 2008; Wallace, HarbeckWeber, Whiteside, \& Harrison, 2011; Wicksell, Lekander, Sorjonen, \& Olsson, 2010; Wicksell, Olsson, \& Melin, 2009). 
This consistency in results has provided important evidence with regard to the utility and generalizability of ACT measures in chronic pain. In addition, the diversity in clinical setting and sample has provided support regarding issues of generalizability and relevance of the model. There are, however, at least two difficulties that are presented by the analytic approach that has been utilized thus far.

The first concerns the potential for disorganized and fragmented development as separate measures of distinct ACT processes, or discrete subsets of these processes, are independently evaluated in relation to the overarching theoretical model. Unfortunately, it is difficult to conceptualize convergence or divergence among these related measures, and consequently the specific process(es) they are meant to assess, when they are utilized in separate studies. In essence, to those new or unfamiliar with the area, the development process can look haphazard or piecemeal and this may diminish clarity, increase confusion, or perhaps even heighten the probability of misapplication.

The second concern is principally statistical. The majority of studies that have investigated the relevance of these ACT-related processes have used an approach based primarily on linear regression, which has focused on the determination of the amount of variance in patient functioning that is accounted for by the ACT-related measures. While this approach has provided supportive evidence with regard to construct validity by indicating that these measures often strongly relate to patient functioning, the risk is that regression analyses are ill suited to independent variables that are highly correlated with one another, as these variables, in a sense, "compete" for shared variance and the statistical parcelling out of this shared variance can significantly affect the pattern of results (Tabachnick \& Fidell, 2012). Reliance on regression approaches alone is therefore unlikely to allow for a comprehensive examination of the ACT model as the component processes share a conceptual overlap and can therefore be expected to both correlate with one another and share variance when used to statistically predict aspects of patient functioning. Statistical approaches that are more robust for use with correlated measures, such as Structural 
Equation Modelling (SEM), are therefore necessary to allow for a more complete evaluation of the ACT model in chronic pain.

Given these two issues, there is a need for a more comprehensive statistical evaluation of the ACT model in chronic pain, which was the primary purpose of the present analyses. Multiple aspects of psychological flexibility and patient functioning were assessed in a sample of individuals with chronic pain via a battery of standardized self-report questionnaires. Multivariate analyses were used to examine whether a statistically sound model of the ACT processes could be identified. Next, aspects of patient functioning, including pain intensity, disability, and emotional distress, were also evaluated to determine whether there were reliable and predictable relations between the model of ACT processes on the one hand and these aspects of patient functioning on the other.

\section{Methods}

\section{Participants}

All participants attended an assessment appointment within an interdisciplinary pain rehabilitation service located in Staffordshire, UK. In total, data were collected from 274 of the $292(93.8 \%)$ consecutive patients seen by the service over a 30 month period. Participant age averaged 51.7 years $(S D=14.8)$. The majority were female $(71.9 \%)$ and White European (96.1\%). Most were married or co-habitating (63.8\%; Divorced, 13.1\%; Single, $14.1 \%$; Widowed, 8.6\%). Participants averaged 12.8 years of formal education ( $S D=$ 2.8 years), with the majority having completed the compulsory course of primary and secondary school $(35.7 \%)$ or less $(34.3 \%)$. Only a small proportion completed a technical degree $(16.4 \%)$, attended some University $(6.4 \%)$, or completed a Bachelor's $(4.3 \%)$ or postgraduate degree (2.5\%). A minority were working (24.3\%) and just over half were receiving wage replacement or disability benefit payments (55.1\%).

Pain duration ranged from 0.75 years to 47.7 years with a median duration of 7.6 years. Pain locations were varied with most presenting with low back pain (54.9\%; full body, 14.4\%, lower limb, 10.5\%; neck or mid-back pain, 9.4\%; upper limb, 6.5\%; other, $4.3 \%$ ). The majority also indicated more than one primary pain site $(70.9 \%)$ and presented with either no 
specific pain diagnosis or one that was of a general nature (e.g., "chronic pain syndrome", "post-surgical pain", 71.8\%). When a specific diagnosis was indicated, the most frequent was fibromyalgia (15.4\%), with smaller proportions (all less than $4.0 \%$ ) reporting other pain diagnoses (e.g., sciatica, peripheral neuropathy, spondylosis, hypermobility). All patients had received a variety of previous treatments for pain, with the most frequent including analgesic medications (87.9\%), physiotherapy (65.6\%), transcutaneous electrical nerve stimulation (53.6\%), injections (34.6\%; average number of injections $=3.6, S D=4.4)$, acupuncture $(32.7 \%)$, surgery $(25.7 \%$; mean number of surgeries $=1.5, S D=0.4)$, chiropractic treatment or osteopathy (28.9\%), and counselling or psychotherapy $(21.1 \%)$.

\section{Measures}

All participants completed a battery of standardized self-report questionnaires prior to their assessment appointment. A short questionnaire was included which assessed demographic and pain-related details, such as work status, receipt of income replacement/disability benefits, and details of pain onset and location. Numerical rating scales were used to evaluate current pain intensity, as well as least, most, and usual pain intensity in the previous week. These scales ranged from 0 (no pain) to 10 (worst possible pain). The total number of pain-related medical visits, including primary, secondary/tertiary, and emergency care, in the preceding three months was also recorded. Finally, a tally of the number of classes of analgesic medications being taken for pain was calculated (i.e., opioids, NSAIDS, tricyclic antidepressants, muscle relaxants, sedatives, anticonvulsants, selective serotonin reuptake inhibitors, over-the-counter analgesics).

For the measures of psychological flexibility, selection was based on their history of usage in chronic pain, positive psychometric characteristics, reliable relations with aspects of patient functioning, and hypothesized coverage of the six ACT processes. Specific rationales for each measure are included below.

\section{Measures of psychological flexibility.}

Brief Pain Coping Inventory - 2 (BPCl-2). The BPCl-2 (McCracken \& Vowles, 2007 ) is a 19 item measure of coping behaviors in response to the experience of chronic 
pain. Patients are asked to indicate how many days in the past week they responded to pain in the ways described in each item. Factor analysis has indicated two subscales (McCracken \& Vowles, 2007). The first (8 items) includes more traditionally conceived coping responses such as activity pacing, relaxation, exercise, distraction, and positive self-statements. The second (11 items) includes coping responses reflecting psychological flexibility relating to acceptance of and willingness to have pain or distress (e.g., struggled to get control of pain reverse scored), broad contact with the present moment (e.g., remained aware of pain while staying aware of the larger situation), and flexible engagement in values-based activity with pain present (e.g., did what works best for goals in life regardless of feelings at the time). Only the Psychological Flexibility Coping subscale was used in the present analysis. Previous analyses have indicated this subscale has reliable relations to measures of patient functioning (McCracken \& Vowles, 2007), is responsive to ACT-based treatment interventions (Vowles \& McCracken, 2010), and has adequate internal consistency (e.g., Cronbach's $\alpha>$.70; McCracken \& Vowles, 2007). To our knowledge, test-retest reliability has not been evaluated.

Chronic Pain Acceptance Questionnaire (CPAQ).The CPAQ (McCracken, Vowles, \& Eccleston, 2004) includes 20 items evaluating acceptance and willingness in relation to the experience of chronic pain. Respondents are asked to rate the degree to which each item applies to them on a 0 (never) to 6 (always) scale. The measure has two subscales. The first, labeled Activity Engagement (11 items), evaluates the extent to which behaviors are restricted or limited by pain and related experiences (e.g., "I am getting on with the business of living no matter what my level of pain is."). The second, labeled Pain Willingness (9 items) evaluates the degree of effort directed at controlling pain and related experiences (e.g., "I would gladly sacrifice important things in my life to control this pain better" - reverse scored). The CPAQ had been used across a number of pain settings and studies have consistently provided evidence of reliability (e..g, Cronbach's $\alpha$ and test-retest reliability in excess of 0.80 ) and validity, prospective utility, and dependable relations with key aspects of 
patient functioning (see Reneman, Dijkstra, Geertzen, \& Dijkstra, 2010 and Vowles \& Thompson, 2011 for reviews).

Chronic Pain Values Inventory (CPVI). The CPVI (McCracken \& Yang, 2006) evaluates importance and success in six domains of valued activity, including family, intimate/close interpersonal relations, friends, work, health, and personal growth/learning. Importance and success in living are separately rated for each domain on a zero (not at all important/successful) to five (extremely important/successful) scale. Three scales can be calculated, values importance, values success, and the discrepancy between importance and success. The values success score was used in the present analyses, as it has been the most widely used in previous analyses and there is support for its psychometric properties (McCracken \& Yang, 2006; Vowles \& McCracken, 2008; Vowles, McCracken, \& Zhao-O'Brien, 2011). Previous work examining internal consistency has indicated Cronbach's $\alpha=0.83$ (McCracken \& Yang, 2006). To our knowledge test-retest reliability has not been evaluated.

Self-Compassion Scale (SCS). The SCS (Neff, 2003) evaluates various aspects of self-compassion and stems from emerging scientific work related to mindfulness and its influence on well-being. The measure has 26 items and six subscales. Subscale labels include Over-identification (e.g., "When something upsets me I get carried away with my feelings." - reverse scored), Isolate (e.g., "When I think about my inadequacies, it tends to make me feel more separate and cut off from the rest of the world." - reverse scored), SelfJudgement (e.g., "I'm disapproving and judgmental about my own flaws and inadequacies." - reverse scored), Common Humanity (e.g., "When things are going badly for me, I see the difficulties as part of life that everyone goes through."), Mindfulness (e.g., "When something painful happens I try to take a balanced view of the situation."), and Self-Kindness (e.g., "I'm kind to myself when I'm experiencing suffering."). Although the SCS was not developed specifically from within the ACT theoretical framework of psychological flexibility, the subscales appear to match quite closely with the "mindfulness" processes specified within ACT (Hayes, Levin, Plumb-Vilardaga, Villatte, \& Pistorello, 2013), including acceptance and 
defusion, as well as moment-to-moment awareness and self-as-context which has been less frequently measured in chronic pain treatment settings. Previous work in non-pain samples has supported the psychometric properties of the subscales in terms of internal consistency (range Cronbach's $\alpha=0.75$ to 0.81 ) and test-retest reliability (range across subscales 0.80 to 0.88 ; Neff, 2003; Neff, Rude, \& Kirkpatrick, 2007).

Measures of functioning. In addition to assessing pain intensity, pain-related healthcare use, and prescribed classes of analgesic medications for pain, three self-report measures were used to quantify patient physical and emotional functioning. Depression was assessed using the British Columbia Major Depression Inventory (BCMDI; Iverson \& Remick 2004), pain-related anxiety was measured using the short form of the Pain Anxiety Symptoms Scale (PASS; McCracken \& Dhingra, 2002), and disability was measured using the three major subscales of the Sickness Impact Profile (SIP; Bergner, Bobbitt, Carter, \& Gilson, 1981), including physical disability (e.g., mobility, ambulation), psychosocial disability (e.g., social functioning, alertness, communication), and independence-related disability (e.g., work, eating, home management). Each of these measures has shown acceptable reliability, validity, and utility in individuals with chronic pain (Vowles, Gross, \& McCracken, 2007).

\section{Analytic Approach}

All analyses were conducted using Mplus version 7.11 (Muthén \& Muthén, 2012). Across all analyses, maximum likelihood (ML) algorithms were used to address missing data. In brief, ML estimates provide the estimated variance-covariance matrix for available data, and therefore all available data were included in all analyses. Maximum Likelihood is a robust and preferred method of addressing missing data, assuming the data are missing at random (Allison, 2009; Enders, 2001; Schafer \& Graham, 2002). Overall, missing data was rare with $6.2 \%$ of responses missing at the item level across the entire sample.

Data analysis was performed in four steps. First, the integrity of the data was inspected through the evaluation of data distributions and scatterplots and by conducting 
sensitivity analyses using pattern mixture models (Enders, 2011) to determine the degree to which missing data impacted observed results.

Second, two exploratory factor analyses (EFA) were performed. The first included measures of psychological flexibility and the second included measures of patient functioning. For each EFA, several factor models were evaluated. Given that no firm databased guides were available with regard to the ideal number of factors for either EFA, we were guided by existing theoretical and conceptual work in our interpretation of the optimal number of factors. For example, as noted above, with regard to psychological flexibility, Hayes and colleagues $(1999 ; 2012)$ specify six processes and three pairs of response options. With regard to measures of functioning, the consensus statement of the Initiative on Methods, Measurement, and Pain Assessment in Clinical Trials group (IMMPACT; Turk et al., 2008) was used to guide factor interpretation. Specifically, three core domains of functioning are highlighted by IMMPACT; pain intensity, physical functioning, and emotional distress. Interpretation of the EFA's was based on evaluation of Eigenvalues and Scree plots, as well as parsimony and interpretability.

Third and finally, SEM was used to evaluate the fit of a full model, which incorporated measures of psychological flexibility and their predicted relations with measures of patient functioning. For these analyses, a unit loading identification constraint was applied for the scaling of latent variables by fixing a factor loading at 1 .

For both the EFA and SEM analyses, the primary statistic used to evaluate model fit was the Root Mean Square Error of Approximation (RMSEA). Values closer to zero indicate better fit. MacCallum and colleagues (1996) have suggested cut-points of $0.01,0.05$, and 0.08 for excellent, good, and mediocre fit, respectively, while Hu and Bentler (1999) suggest a value of lower than 0.06 for good fit. For the RMSEA, $90 \% \mathrm{Cl}$ was calculated, and a significance test for "close" model fit was conducted $(p<.05$ indicates model fit is worse than "close"; Bryne, 2001). We also utilized Hu and Bentler's (1999) recommended two-index presentation strategy, which included an absolute fit index, the standardized root mean squared residual (SRMR), as well as an incremental fit index, which was the Tucker-Lewis 
Index (TLI) in the case of the present analyses. For the SRMR, close fit is indicated by values below .08, while TLI values at or above 0.95 indicate close fit (Hu \& Bentler, 1999).

\section{Results}

\section{Data Integrity}

The left-sided panels of Tables 1 and 2 provide descriptive information for all study measures. Internal consistency ratings (Cronbach's $\alpha$ ) for all measures were above 0.77 (range: $0.77-0.92$ ). Evaluation of data distributions indicated that the majority of variables were normally distributed and non-kurtotic. The only exception was for the variable assessing highest pain in the past week, for which there was evidence of significant kurtosis (value $=2.43$ ). Essentially, and as would be expected, the majority of patients provided a rating that was near the maximal end of the scale, with $85.2 \%$ rating their maximum pain in the past week as an 8,9 , or 10 . Given this issue, as well as previous work that has made use of similar composite scores with and without the inclusion of a maximum pain rating (e.g., Jensen, Turner, Romano, \& Fisher, 1999; McCracken et al., 2004), we excluded highest pain rating from the remainder of the analysis. Sensitivity analyses indicated consistent results across models (with and without the missing data indicators), which suggests that the degree of missing data did not substantially influence results.

\section{Exploratory Factor Analysis of Measures of Psychological Flexibility}

As noted, 10 measures of psychological flexibility were utilized, including the Values Success subscale of the CPVI, both subscales of the CPAQ, the Psychological Flexibility Coping subscale of the BPCI, and the six subscales of the SCS. Results of the initial EFA indicated a lack of convergence for models with five or greater factors. Across all models, however, there was evidence of mediocre to poor model fit (e.g., all RMSEA's > .09), which appeared to be primarily due to crossloading for two measures, the Pain Willingness subscale of the CPAQ and the Self-Kindness subscale of the SCS. While various strategies were considered to address these cross-loadings, it was ultimately decided that the most parsimonious and statistically sound solution was to exclude them from further analysis. In part, this decision was based on statistical advice that observed variables which load on to 
more than one latent variable increase identification problems within measurement models and are best avoided (O’Brien, 1994).

The factor analysis was therefore repeated without these two subscales. As with the previous EFA, there was a lack of convergence for models with five or greater factors. Evaluation of Eigenvalues $(3.7,1.5,1.1,0.5)$ and the Scree plot suggested that either a single factor or three factor solution were most appropriate. We also investigated fit for a two factor solution. Model fit for the single factor solution was poor (RMSEA $=0.22 ; 90 \% \mathrm{Cl}: 0.20$ $-0.25 ; \mathrm{p}$ "close" fit $<0.001$; SRMR $=.14 ; \mathrm{TLI}=0.52 ;$ ), as was fit for a two factor solution (RMSEA $=0.16 ; 90 \% \mathrm{Cl}: 0.13-0.19 ; \mathrm{p}$ "close" fit $<0.001 ;$ SRMR $=.08 ; \mathrm{TLI}=0.76$ ). Model fit for the three factor model was acceptable (RMSEA $=0.06 ; 90 \% \mathrm{Cl}: 0.02-0.11$; $p$ "close" fit $=0.23 ;$ SRMR $=.02 ; \mathrm{TLI}=0.96$ ). The four factor solution was not interpretable as there was a negative estimated residual variance for one variable (Mindfulness), which is indicative of an inadmissible factor solution as it indicates a single item factor or a factor within which a single variable is accounting for the vast majority of the variance (Muthén \& Muthén, 2012).

Given these results, a three factor solution was deemed most appropriate and was further evaluated by inspecting individual variable loadings, as well as parsimony and interpretability of the factor solution. Factor loadings indicated good loading onto a unique factor by all variables (all primary loadings were in excess of 0.58 ) and no evidence of crossloading (no secondary loading exceeded 0.25 ). Rotated factor loadings are located in the right hand panels of Table 1.

Factor interpretation was fairly straightforward. The first factor was composed of three subscales of the SCS; these consisted of Self-Judgement, Isolation, and Overidentification. As the item composition of each of these subscales chiefly involves acceptance and willingness in relation to difficult circumstances, as well as not being caught up, dominated or fused with these circumstances, two of the ACT processes, Defusion and Acceptance, were used to label this factor. The second factor was composed of Activity Engagement (CPAQ), Values Success (CPVI), and Psychological Flexibility Coping (BPCI). 
As the item content of these measures largely relates to values-based actions within a context of continuing pain, this factor was labelled Values and Committed Action. The third and final factor was composed of the remaining subscales of the SCS, Common Humanity and Mindfulness, which relate to aspects of both Self-as-Context and Moment-to-Moment Awareness. The factor was therefore labelled as such.

\section{Exploratory Factor Analysis of Measures of Functioning}

As with the measures of Psychological Flexibility, 10 measures of functioning were utilized, including three measures of pain intensity (usual, lowest, and current), the three disability subscales of the SIP (physical, psychosocial, and independence disability), measures of depression and pain-related fear, the number of pain-related medical visits over the preceding three months, and the number of classes of prescribed analgesics for pain.

Results of the initial EFA indicated a lack of convergence for models of four factors or greater than six factors. Furthermore, while model fit was acceptable for some of these factor solutions, there was evidence of crossloading for the Psychosocial Disability subscale of the SIP, particularly for models with greater than four factors. This variable was excluded from further analyses and the EFA was repeated. These analyses also indicated a lack of convergence for models with four factors or with six or more factors. Evaluation of Eigenvalues $(3.7,1.4,4.2,0.9,0.6)$ and the Scree plot suggested that a single factor solution or three factor solution was most appropriate. We investigated fit for a two and five factor solution as well. Model fit for the single factor solution was poor $(\mathrm{RMSEA}=0.21 ; 90 \% \mathrm{Cl}$ : $0.19-0.23 ; \mathrm{p}$ "close" fit $<0.001 ; \mathrm{SRMR}=.11 ; \mathrm{TLI}=0.50 ;$ ), as was fit for a two factor solution (RMSEA = 0.12; 90\% Cl: $0.10-0.14 ; p$ "close" fit < 0.001; SRMR = .06; TLI = 0.84). Model fit for the three factor model was acceptable (RMSEA $=0.03 ; 90 \% \mathrm{Cl}: 0.001-0.07 ; p$ "close" fit $=0.76 ;$ SRMR $=.02 ; \mathrm{TLI}=0.99)$. The five factor solution was not interpretable as there were negative estimated residual variances for two variables which loaded on two separate factors (Depression, Medical Visits).

Given these results, a three factor solution was deemed most appropriate and was further evaluated by inspecting individual variable loadings, as well as parsimony and 
interpretability of the factor solution. Factor loadings indicated adequate loading onto a unique factor by all variables (all primary loadings were in excess of 0.32 ) and no evidence of cross-loading (no secondary loading exceeded 0.23 ). Rotated factor loadings are located in the right hand panels of Table 2.

Factor interpretation was straightforward. The two remaining disability subscales loaded onto the same factor alongside the number of prescribed classes of analgesics. Given that the SIP is a measure of disability and greater rates of analgesic use are often associated with higher levels of disability (e.g., Kidner et al., 2009), the factor was simply labelled Disability. The ratings of pain all loaded onto a single factor, which was labelled as Pain Intensity. Finally, pain-related fear, depression and number of pain-related medical visits over the preceding three months loaded onto the last factor, which was labelled as Emotional Distress.

\section{Structural Equation Modelling (SEM)}

The final analytic step involved an evaluation of the relation between the psychological flexibility variables on the one hand and measures of functioning on the other. Within the model, we anticipated that the factors involving psychological flexibility would correlate with one another and that each of these factors would be related to each of the three factors involving patient functioning. We further anticipated that the pain intensity, emotional distress, and disability latent variables would correlate with one another.

Initial inspection of results indicated a weak, non-significant relation between the latent variables of Defusion/Acceptance and Pain Intensity, $B=-.02, p=.84$, as well as a non-significant loading of the Medical Visits variable onto the latent factor of Disability, $B=$ $.08, p=.20$. These two relations were therefore removed sequentially from the model.

Results for the modified model indicated acceptable fit with the data (RMSEA $=0.06$; $90 \% \mathrm{Cl}: 0.05-0.07 ; \mathrm{p}$ "close" fit $=0.09 ; \mathrm{SRMR}=.05 ; \mathrm{TLI}=0.94)$. Standardized regression weights between the aspects of psychological flexibility and measures of functioning were all significant and correlations amongst all latent variables of psychological flexibility were significant, as were correlations amongst the latent variables of patient functioning (See 
Figure 1 for specific values, all $p$ 's <.01). All relations were in the expected direction such that higher scores in aspects of psychological flexibility were associated with better functioning.

Standardized regression weights between observed variables and their specified latent variable were also significant for all variables and were in the expected direction. The weight was modest for the classes of pain medications variable, $B=0.23(p<.001)$, but was deemed acceptable given overall model fit and the fact that this aspect of functioning is highly clinically relevant with regard to chronic pain (e.g., Gatchel \& Okifuji, 2006; Turk et al., 2008). The other weights ranged from $B=0.71$ to $B=0.89$ (all $p$ 's $<.001$ ) with mean overall $B=0.78$. After considering the overall pattern of results, model fit was deemed adequate and no further modifications were made. (Also see Footnote 1).

\section{Discussion}

The primary purpose of the present analyses was examine the ACT model, as represented by measures of the identified processes of psychological flexibility, in relation to specific aspects of functioning in individuals with chronic pain. A number of preliminary statistical analyses were performed to help inform a structure for the final model, the fit of which was ultimately examined via SEM. Fit of this final model to the data was acceptable, as the ACT processes both correlated with one another and generally related to latent variables of pain intensity, emotional distress, and disability. In brief, the pattern of findings here suggests that there is reasonable coherence between the data, the model, and the model's relations with key aspects of functioning in those with chronic pain.

With regard to the pattern of results concerning only the ACT process measures, the data seemed to be separable in ways that were interpretable and coherent. It is worth noting, however, that the indicated three factor solution differs from the original conceptualization of six processes of psychological flexibility. From a statistical perspective, it is perhaps realistic to expect more closely related processes to highly correlate with one another. For example, defusion and acceptance loaded onto a single factor. Both processes relate to perspective and willingness to have difficult experiences when change attempts are 
ineffective or contribute to further problems. The same seems to be true of the second and third factors to emerge following the factor analysis. Values and committed action are components of the model that focus on responses to difficult circumstances which consistently move one in a direction of more full, free, and vital living. Present focusedawareness and self-as-context share an emphasis on one's relation to ongoing experiences and, in a sense, whether one is "caught up" and overwhelmed by those experiences or making a distinction between the experiences and the person having them. Further, the magnitude of correlations among the factors, which were in the medium range with regard to overall magnitude, was strong enough to suggest they are closely related, but not so strong as to suggest complete overlap. To our knowledge, these analyses provide the most comprehensive evaluation of the ACT model to date, although these findings might be applicable only to chronic pain, or perhaps only to this particular sample of individuals, and are therefore best viewed as preliminary at this stage.

During the exploratory factor analyses, three measures were excluded from further analyses due to factor crossloading. A review of the item content of all three of these scales seemed to suggest they contained items that were fairly broad in content, which perhaps indicates this crossloading was to be expected. Ideally, we could have included all measures within the analyses or selected measures that would not crossload, although there is an absence of data to guide such selection. It seems that there are two possible avenues for progress in the next stages of measure development in this area.

The first is to construct measures that evaluate the ACT model broadly, including all component processes. The second is to move towards greater precision in measurement by specifically investigating individual processes or components of the model as they change over time and treatment. This latter strategy may allow for more clear investigation of processes of change. For example, researchers in this area are increasingly interested in the investigation of change in component ACT processes within treatment and how these changes relate to progress and improvement (e.g., Forman et al., 2012; Meuret, WolitzkyTaylor, Twohig, \& Craske, 2012; Vowles, Witkiewitz, Sowden, \& Ashworth, in press). If 
fruitful, this specific line of investigation holds promise in more fully illuminating the dynamic change in ACT processes, or other adaptive psychological mechanisms of change, as treatment progresses.

The final analytic step involved an examination of a wider model, including both ACT processes and key aspects of patient functioning. There are at least three points that seem important to consider.

The first is that the model tested was quite complex and sophisticated, in that it incorporated both a model of psychological processes and aspects of functioning that the model is hypothesized to influence. The testing of a theorized model of psychological functioning in relation to aspects of patient functioning is perhaps one of the more unique aspects of these analyses.

The second point concerns the pain variables. The relatively strong relations between two of the three factors to pain is interesting and likely reflects the complexity inherent in any verbal rating of pain (i.e., it is more than simple nociception; e.g., Campbell \& Vowles, 2008). The pattern of results here may serve as a reminder that the pain experience is quite complex and likely consists of both nociception and aspects of what may be collectively termed as "suffering" and that it is important not to confound these two aspects of the pain experience as one is likely to be more treatable than the other (see Fordyce, 1988).

Finally, from a statistical perspective, the strength and direction of relations amongst various aspects of the model displayed in Figure 1 are noteworthy. The relations between the psychological flexibility processes on the left side bear reasonably robust relations with aspects of functioning in each case. Bearing in mind that causality cannot be inferred from these findings, it seems sufficient to conclude that these data provide the first indication that the component processes of ACT model, collectively considered, appear highly relevant to important aspects of patient functioning in chronic pain.

There are also limitations to consider. First, data were collected at a single point and causal inferences are not possible. Second, data were almost exclusively self-report and this invariance in assessment method may have influenced the pattern of results. In particular, 
the addition of overt behavioral measures (e.g., physical performance tasks; Harding et al., 1994) to our assessment battery may allow greater insight into the relations amongst measures of ACT processes and functioning. Third, while our analyses indicated that missing data did not appear to have a significant influence on the results, we cannot state with certainty the results would have been identical if no missing data were present. Fourth, our sample was predominantly female and White European, which potentially limits the generalizability of results to samples with different demographic characteristics. While the CPAQ has been used in many groups with differing demographic characteristics (Veehof, Oskam, Schreurs, \& Bohlmeijer, 2011; Vowles \& Thompson, 2011), the other measures of the ACT model have not seen such diversity in sample characteristicsl. Fifth, as noted, during the exploratory factor analyses, three measures were excluded from further analyses due to factor crossloading and it would have been ideal to include all measures.

Furthermore, it is unfortunate that the Self-as-Context/Moment to Moment Awareness factor consisted of items that were entirely negatively scored while the other two factors consistent of positively scored items. This raises the possibility of a method effect within the analyses (cf. DiStefano \& Motl, 2006), at least with regard to these subscales as the Pain Willingness subscale of the CPAQ is also negatively worded and did not load on this factor. Sixth, while measures were selected with the purpose of broad and comprehensive evaluation of as many ACT processes as possible, practical restrictions meant only a subset of all possible measures were used and issues like wording of items or pre-existing factor structures may have had an influence on outcomes (e.g., SCS; CPAQ).

Considering these limitations collectively, it is possible that participants with different characteristics would yield a different pattern of results. It is possible, therefore, that the generalizability of this pattern of findings may be limited to samples or treatment settings which possess similar characteristics. Replication and extension of this work will benefit from addressing these issues, chiefly by including variation in measurement method and timing of assessment, larger samples, and enhancing response rates. 
At present, the approach to human suffering advocated by ACT seems well-suited to chronic pain, as there are now several appropriate measures and the outcome data are strong. While important work remains, including the need for prospective designs examining changes in the ACT processes over the course of treatment, the present analyses indicate good support for the model overall and suggest it is highly appropriate for use in the study of chronic pain. 


\section{Footnote}

${ }^{1}$ Because of the preponderance of women in the sample, we also conducted the final SEM models for women only. The results were identical (e.g., nonsignificant values in the initial model) with acceptable fit in the final model (RMSEA $=0.06 ; 90 \% \mathrm{Cl}: 0.05-0.08$; $p$ "close" fit $=<0.06$, SRMR $=.06 ; \mathrm{TLI}=0.93$ ). 


\section{Disclosure Statement}

The authors have no conflicts of interest to declare. 


\section{References}

Allison, P. D. (2009). Missing Data. In R. E. Millsap \& A. Maydeu-Olivares (Eds.), The SAGE handbook of quantitative methods (pp. 72-89). Thousand Oaks, CA: Sage.

Bryne, B. M. (2001). Structural equation modeling with AMOS: Basic concepts, applications, and programming. Mahwah, NJ: Lawrence Erlbaum.

Campbell, W. I., \& Vowles, K. E. (2008). Practical methods for pain intensity measurements. In A. Rice, H. Breivik, W. I. Campbell, \& M. K. Nicholas (Eds.), Clinical pain management: Practice and procedures (2nd ed., pp. 12-27). New York: Hodder Arnold.

DiStefano, C., \& Motl, R. W. (2006). Further Investigating Method Effects Associated With Negatively Worded Items on Self-Report Surveys. Structural Equation Modeling, 13, 440-464. doi:10.1207/s15328007sem1303_6

Elander, J., Robinson, G., Mitchell, K., \& Morris, J. (2009). An assessment of the relative influence of pain coping, negative thoughts about pain, and pain acceptance on healthrelated quality of life among people with hemophilia. Pain, 145, 169-175. doi:10.1016/j.pain.2009.06.004

Enders, C. K. (2001). A primer on Maximum Likelihood algorithms available for use with missing data. Structural Equation Modeling, 8, 128-141. doi:10.1207/S15328007SEM0801_7

Enders, C. K. (2011). Missing not at random models for latent growth curve analyses. Psychological Methods, 16, 1-16. doi:10.1037/a0022640

Fordyce, W. E. (1988). Pain and suffering: A reappraisal. American Psychologist, 43, 276 283. doi:10.1037/0003-066X.43.4.276

Forman, E. M., Chapman, J. E., Herbert, J. D., Goetter, E. M., Yuen, E. K., \& Moitra, E. (2012). Using session-by-session measurement to compare mechanisms of action for Acceptance and Commitment Therapy and Cognitive Therapy. Behavior Therapy, 43, 341-354. doi:10.1016/j.beth.2011.07.004 
Gatchel, R. J., \& Okifuji, A. (2006). Evidence-based scientific data documenting the treatment and cost-effectiveness of comprehensive pain programs for chronic nonmalignant pain. Journal of Pain, 7, 779-93. doi:10.1016/j.jpain.2006.08.005

Gatchel, R. J., Peng, Y. B., Peters, M. L., Fuchs, P. N., \& Turk, D. C. (2007). The biopsychosocial approach to chronic pain: scientific advances and future directions. Psychological Bulletin, 133, 581-624. doi:10.1037/0033-2909.133.4.581

Harding, V. R., de C Williams, A. C., Richardson, P. H., Nicholas, M. K., Jackson, J. L., Richardson, I. H., \& Pither, C. E. (1994). The development of a battery of measures for assessing physical functioning of chronic pain patients. Pain, 58, 367-375. doi:10.1016/0304-3959(94)90131-7

Hayes, S. C., Levin, M. E., Plumb-Vilardaga, J., Villatte, J. L., \& Pistorello, J. (2013). Acceptance and commitment therapy and contextual behavioral science: Examining the progress of a distinctive model of behavioral and cognitive therapy. Behavior Therapy, 44, 180-98. doi:10.1016/j.beth.2009.08.002

Hayes, S. C., Strosahl, K. D., \& Wilson, K. G. (2012). Acceptance and Commitment Therapy: The process and practice of mindful change (2nd ed.). New York: Guilford Press. Hayes, S. C., Villatte, M., Levin, M., \& Hildebrandt, M. (2011). Open, aware, and active: Contextual approaches as an emerging trend in the behavioral and cognitive therapies. Annual Review of Clinical Psychology, 7, 141-168. doi:10.1146/annurev-clinpsy032210-104449

Hu, L. T., \& Bentler, P. M. (1999). Cutoff criteria for fit indexes in covariance structure analysis: Conventional criteria versus new alternatives. Structural Equqation Modeling, 6, 1-55. doi:10.1080/10705519909540118 Iverson, G. L., \& Remick, R. (2004). Diagnostic accuracy of the British Columbia Major Depression Inventory. Psychological Reports, 95, 1241-1247. doi:10.2466/pr0.95.3f.1241-1247 
Jensen, M. P., Turner, J. A., Romano, J. M., \& Fisher, L. D. (1999). Comparative reliability and validity of chronic pain intensity measures. Pain, 83, 157-162. doi:10.1016/S03043959(99)00101-3

Kratz, A. L., Davis, M. C., \& Zautra, A. J. (2007). Pain acceptance moderates the relation between pain and negative affect in Osteoarthritis and Fibromyalgia patients. Annals of Behavioral Medicine, 33, 291-301. doi:10.1080/08836610701359860

MacCallum, R. C., Browne, M. W., \& Sugawara, H. M. (1996). Power analysis and determination of sample size for covariance structure modeling. Psychological Methods, 1, 130-149. doi:10.1037/1082-989X.1.2.130

McCracken, L. M. (2005). Social context and acceptance of chronic pain: The role of solicitous and punishing respnses. Pain, 113, 155-159. doi:10.1016/j.pain.2004.10.004

McCracken, L. M., \& Dhingra, L. (2002). A short version of the Pain Anxiety Symptoms Scale (PASS-20): Preliminary development and validity. Pain Research and Management, 7, 45-50.

McCracken, L. M., Gauntlett-Gilbert, J., \& Vowles, K. E. (2007). The role of mindfulness in a contextual cognitive-behavioral analysis of chronic pain-related suffering and disability. Pain, 131, 63-69. doi:10.1016/j.pain.2006.12.013

McCracken, L. M., \& Vowles, K. E. (in press). Acceptance and Commitment Therapy and mindfulness for chronic pain: Model, process, and progress. American Psychologist. McCracken, L. M., \& Vowles, K. E. (2007). Psychological flexibility and traditional pain management strategies in relation to patient functioning with chronic pain: an examination of a revised instrument. Journal of Pain, 8, 700-707. doi:10.1016/j.jpain.2007.04.008

McCracken, L. M., Vowles, K. E., \& Eccleston, C. (2004). Acceptance of chronic pain: component analysis and a revised assessment method. Pain, 107, 159-166. doi:10.1016/j.pain.2003.10.012 
McCracken, L. M., Vowles, K. E., \& Gauntlett-Gilbert, J. (2007). A prospective investigation of acceptance and control-oriented coping with chronic pain. Journal of Behavioral Medicine, 30, 339-349. doi:10.1007/s10865-007-9104-9

McCracken, L. M., \& Yang, S. (2006). The role of values in a contextual cognitive-behavioral approach to chronic pain. Pain, 123, 137-145. doi:10.1016/j.pain.2006.02.021

McCracken, L. M., \& Zhao-O’Brien, J. (2010). General psychological acceptance and chronic pain $\square$ : There is more to accept than the pain itself. European Journal of Pain, 14, 170175. doi:10.1016/j.ejpain.2009.03.004

Meuret, A. E., Wolitzky-Taylor, K. B., Twohig, M. P., \& Craske, M. G. (2012). Coping skills and exposure therapy in panic disorder and agoraphobia: latest advances and future directions. Behavior therapy, 43(2), 271-84. doi:10.1016/j.beth.2011.08.002

Muthén, L. K., \& Muthén, B. O. (2012). Mplus users guide (Version 7). Los Angeles, CA: Muthén \& Muthén.

Neff, K D. (2003). Development and validation of a scale to measure self-compassion. Self and Identity, 2, 223-250. doi:10.1080/15298860390209035

Neff, Kristin D., Kirkpatrick, K. L., \& Rude, S. S. (2007). An examination of self-compassion in relation to positive psychological functioning and personality traits. Journal of Research in Personality, 41(4), 908-916. doi:10.1016/j.jrp.2006.08.002

O'Brien, R. (1994). Identification of simple measurement models with multiple latent variables and correlated errors. Sociological Methodology, 24, 137-170.

Reneman, M. F., Dijkstra, A., Geertzen, J. H. B., \& Dijkstra, P. U. (2010). Psychometric properties of Chronic Pain Acceptance Questionnaires: a systematic review. European Jounal of Pain, 14, 457-565. doi:10.1016/j.ejpain.2009.08.003

Schafer, J. L., \& Graham, J. W. (2002). Missing data: Our view of the state of the art. Psychological Methods, 7(2), 147-177. doi:10.1037//1082-989X.7.2.147

Tabachnick, B. G., \& Fidell, L. S. (2012). Using multivariate statistics (6th ed.). Needham Heights, MA: Pearson. 
Turk, D. C., Dworkin, R. H., Revicki, D., Harding, G., Burke, L. B., Cella, D., ... Rappaport, B. A. (2008). Identifying important outcome domains for chronic pain clinical trials $\square$ : An IMMPACT survey of people with pain. Pain, 137, 276-285. doi:10.1016/j.pain.2007.09.002

Veehof, M. M., Oskam, M.-J., Schreurs, K. M. G., \& Bohlmeijer, E. T. (2011). Acceptancebased interventions for the treatment of chronic pain: a systematic review and metaanalysis. Pain, 152, 533-542. doi:10.1016/j.pain.2010.11.002

Vowles, K. E., Gross, R. T., \& McCracken, L. M. (2007). Evaluating outcomes in the interdisciplinary treatment of chronic pain: A guide for practicing clinicians. In M. Schatman \& A. Campbell (Eds.), Chronic Pain Management: Guidelines for Multidisciplinary Program Development (pp. 203-220). New York: Informa.

Vowles, K. E., \& McCracken, L. M. (2008). Acceptance and values-based action in chronic pain: a study of treatment effectiveness and process. Journal of Consulting and Clinical Psychology, 76(3), 397-407. doi:10.1037/0022-006X.76.3.397

Vowles, K. E., \& McCracken, L. M. (2010). Comparing the role of psychological flexibility and traditional pain management coping strategies in chronic pain treatment outcomes. Behaviour Research and Therapy, 48, 141-146. doi:10.1016/j.brat.2009.09.011

Vowles, K. E., McCracken, L. M., \& Eccleston, C. (2007). Processes of change in treatment for chronic pain: the contributions of pain, acceptance, and catastrophizing. European Jounal of Pain, 11, 779-787. doi:10.1016/j.ejpain.2006.12.007

Vowles, K. E., McCracken, L. M., McLeod, C., \& Eccleston, C. (2008). The Chronic Pain Acceptance Questionnaire: Confirmatory factor analysis and identification of patient subgroups. Pain, 140, 284-291. doi:10.1016/j.pain.2008.08.012

Vowles, K. E., McCracken, L. M., \& O’Brien, J. Z. (2011). Acceptance and values-based action in chronic pain: a three-year follow-up analysis of treatment effectiveness and process. Behaviour Research and Therapy, 49, 748-755.

doi:10.1016/j.brat.2011.08.002 
Vowles, K. E., \& Thompson, M. (2011). Acceptance and Commitment Therapy for chronic pain. In L. M. McCracken (Ed.), Mindfulness and acceptance in behavioral medicine: Current theory and practice (pp. 31-60). Oakland, CA: New Harbinger Publications.

Vowles, K. E., Witkiewitz, K., Sowden, G., \& Ashworth, J. (in press). Acceptance and Commitment Therapy for chronic pain: Evidence of mediation and clinically significant change following an abbreviated interdisciplinary program of rehabilitation. Journal of Pain. doi:10.1016/j.jpain.2013.10.002

Wallace, D. P., Harbeck-weber, C., Whiteside, S. P., \& Harrison, T. E. (2011). Adolescent acceptance of pain: Confirmatory factor analysis and further validation of the Chronic Pain Acceptance Questionnaire, adolescent version. Journal of Pain, 12, 591-599. doi:10.1016/j.jpain.2010.11.004

Wicksell, R. K., Lekander, M., Sorjonen, K., \& Olsson, G. L. (2010). The Psychological Inflexibility in Pain Scale (PIPS)--statistical properties and model fit of an instrument to assess change processes in pain related disability. European Jounal of Pain, 14, 771.e1-771.e14. doi:10.1016/j.ejpain.2009.11.015

Wicksell, R. K., Olsson, G. L., \& Melin, L. (2009). The Chronic Pain Acceptance Questionnaire (CPAQ)-further validation including a confirmatory factor analysis and a comparison with the Tampa Scale of Kinesiophobia. European Jounal of Pain, 13, 760768. doi:10.1016/j.ejpain.2008.09.003 
Table 1

Descriptive information and rotated (geomin) factor loadings for measures of psychological flexibility.

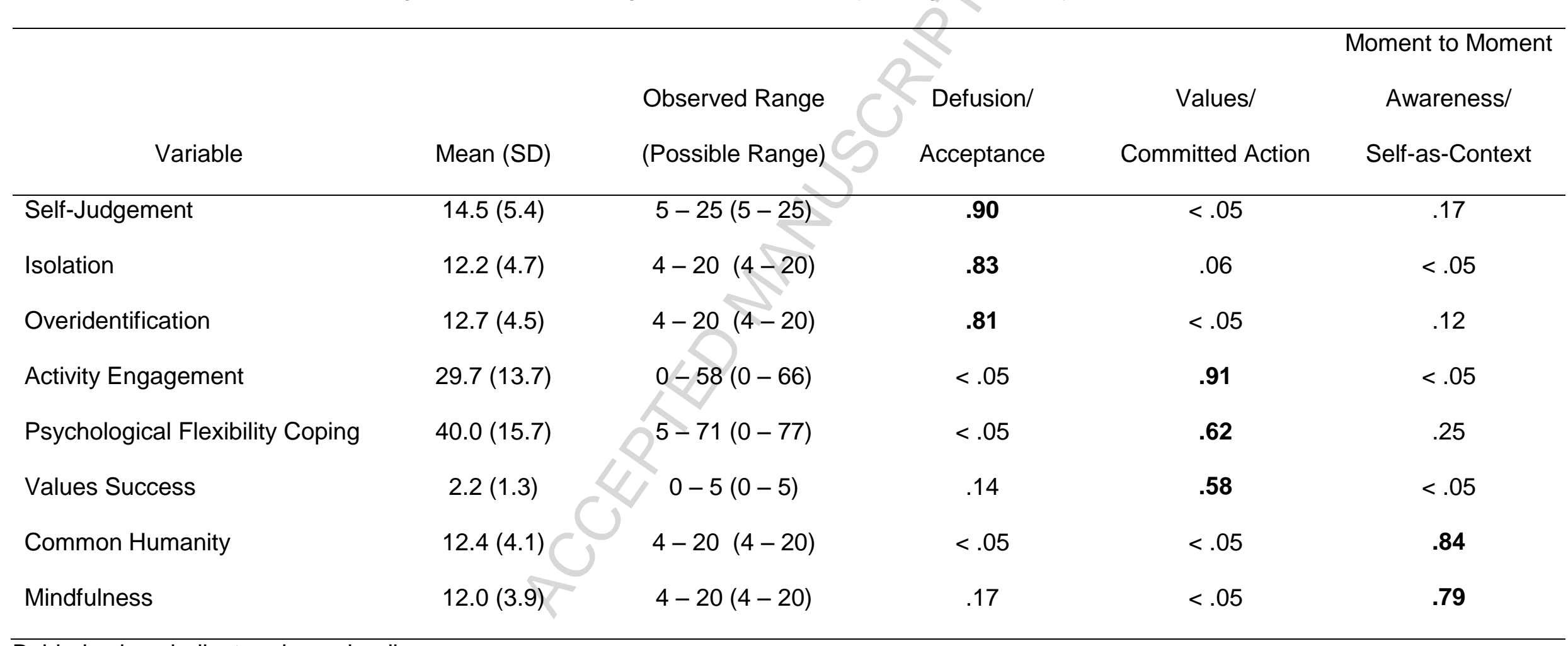

Bolded values indicate primary loadings.

Self-Judgement, Isolation, Overidentification, Common Humanity, Mindfulness, and Self-Kindness were measured by the Self-Compassion Scale; Psychological Flexibility Coping was measured by the Brief Pain Coping Inventory; Values Success was measured by the Chronic Pain Values Inventory; Activity Engagement and Pain Willingness were measured by the Chronic Pain Acceptance Questionnaire.

Descriptive information for the two excluded variables was as follows: Pain Willingness, Mean $=18.6, S D=15.7 ;$ Self-Kindness, Mean $=12.3$, $S D=4.9$. 
Table 2

Descriptive information and rotated factor loadings for measures of functioning.

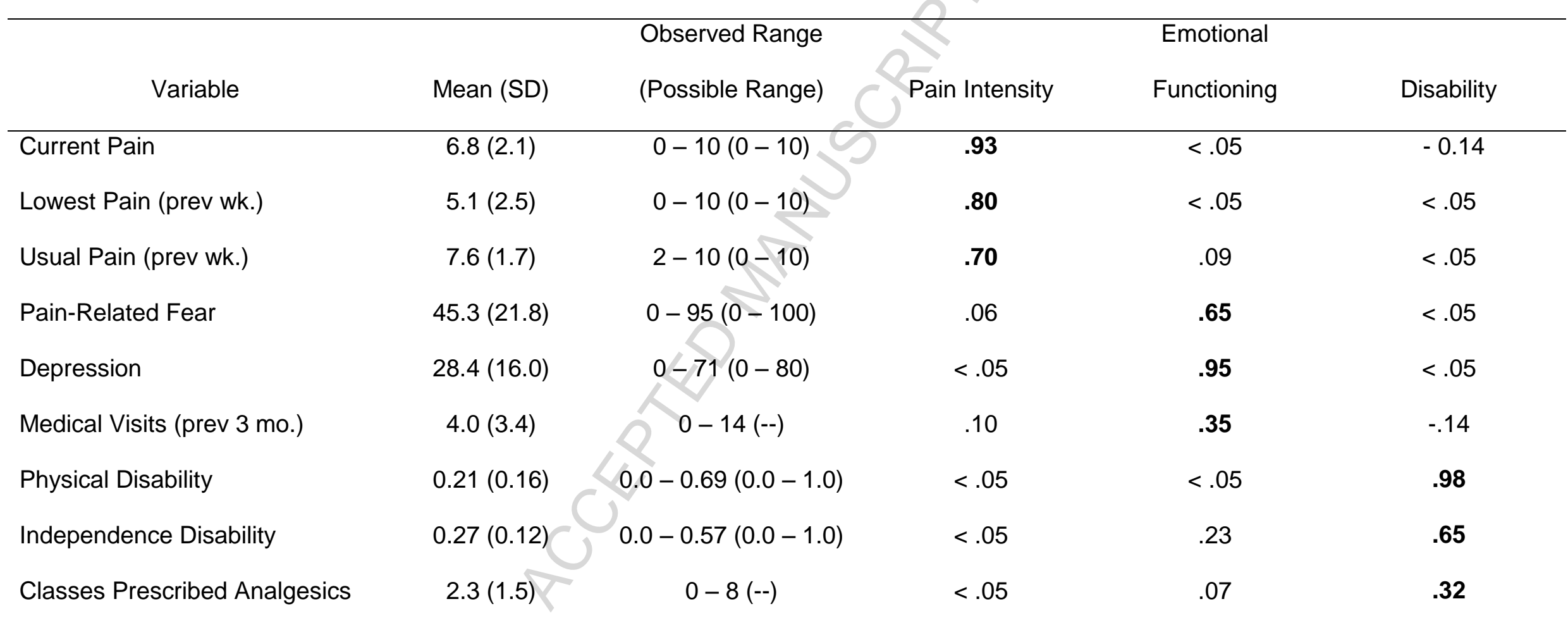

Bolded values indicate primary loadings.

Independence and Physical Disability were measured by the Sickness Impact Profile, Classes of Prescribed Analgesics was a tally of the total number of prescribed classes of medications for pain; Pain intensity variables were assessed via a 0 (no pain) to 10 (worst possible pain) numerical rating scale; Pain-related fear was assessed by the Pain Anxiety Symptoms Scale Short Form; Medical Visits was a tally of the total number of pain-related medical visits (including primary, secondary, tertiary, and emergency care) attended in the previous three months; Depression was measured by the British Columbia Major Depression Inventory.

Descriptive information for the excluded variable of Psychosocial Disability was (Mean $=0.23 ; S D=0.17$ ). 


\section{Figure Caption}

Figure 1. Results of the final SEM model. *Note that the Self-as-Context \& Moment to Moment Awareness latent variable was composed of reverse scored items and this is reflected in the direction of association. 


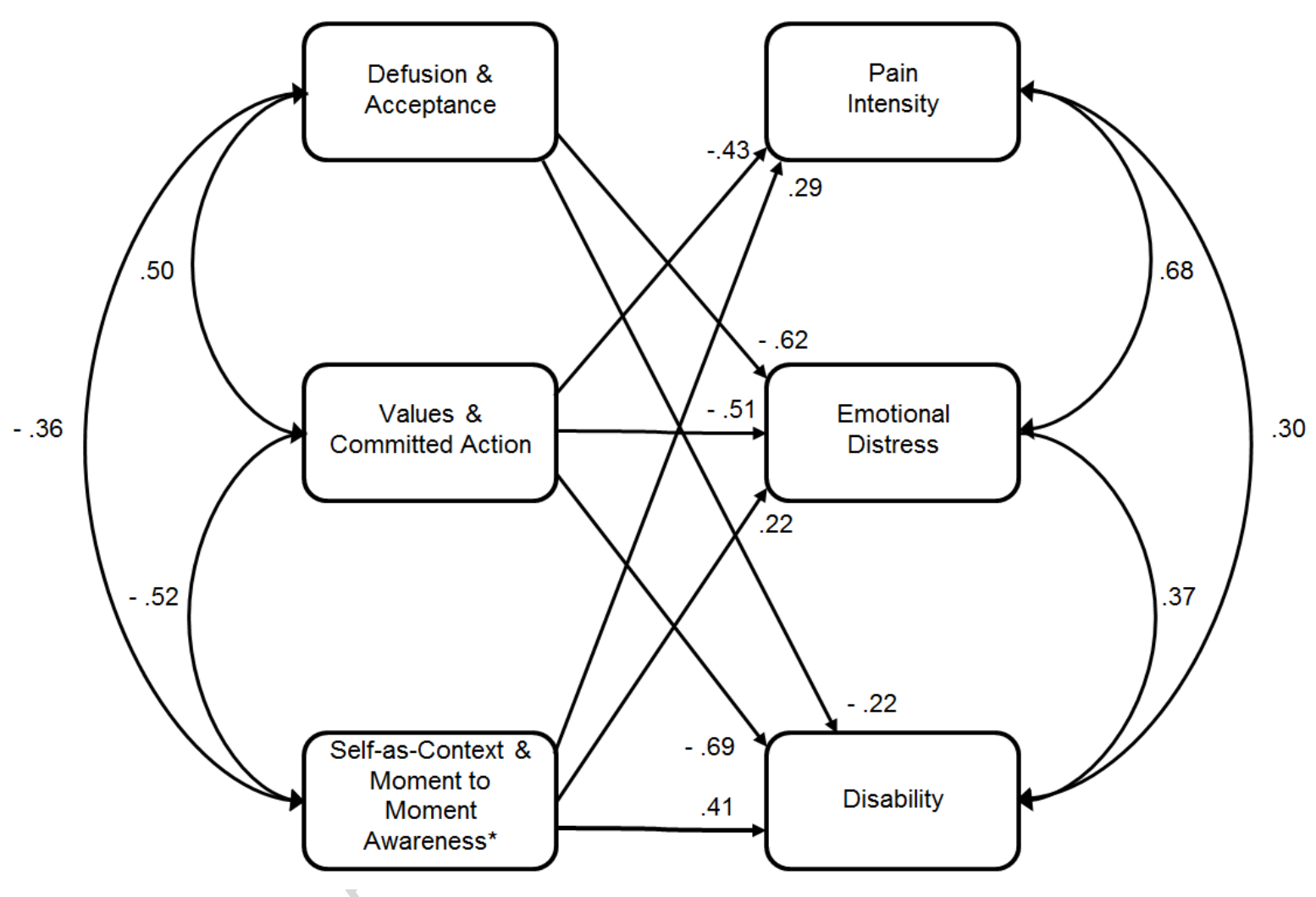


Highlights

- A comprehensive examination of the ACT model in chronic pain was performed.

- Factor analysis indicated moderate relations among the ACT processes, consistent with the model.

- SEM analyses indicated significant relations with key measures of patient functioning.

- This is the first study to comprehensively examine the ACT model; fit with the data was acceptable. 